\title{
Small dose of propofol combined with dexamethasone for postoperative vomiting in pediatric Moyamoya disease patients: a prospective, observer-blinded, randomized controlled study
}

\author{
Jeongmin Kim ${ }^{1,2}$, Gyu Dong Jang ${ }^{3}$, Dong-Suk Kim ${ }^{4}$, and Kyeong Tae Min ${ }^{1,2}$ \\ ${ }^{1}$ Department of Anesthesiology and Pain Medicine, Yonsei University Health System, ${ }^{2}$ Anesthesia and Pain Research Institute, Yonsei \\ University College of Medicine, Seoul, ${ }^{3}$ Department of Anesthesiology and Pain Medicine, Yonsei University Wonju College of Medicine, \\ Wonju, ${ }^{4}$ Department of Pediatric Neurosurgery, Yonsei University Health System, Seoul, Korea
}

Background: For effective postoperative antiemetic management in pediatric moyamoya disease patients receiving fentanyl based postoperative analgesia, a multimodal approach has been recommended. The uncertain efficacy of ondansetron for pediatric neurosurgical patients or the possible antiemetic effect of small dose of propofol motivated us to evaluate the preventive effect of a subhypnotic dose of propofol combined with dexamethasone on postoperative vomiting (POV), especially during immediate postoperative periods.

Methods: In a prospective observer-blind randomized controlled study, we compared dexamethasone $0.15 \mathrm{mg} /$ $\mathrm{kg}$ alone (Group D) with dexamethasone combined with propofol of $0.5 \mathrm{mg} / \mathrm{kg}$ (Group DP) in 60 pediatric patients, aged 4-17 years, who underwent indirect bypass surgery and received fentanyl-based postoperative analgesia. Occurrence of vomiting and pain score (Wong-Baker facial score) and requirement of rescue analgesic and antiemetic were continually measured $(0-2,2-6,6-12$ and $12-24$ postoperative hours). For statistical analysis, in addition to the Fisher's exact test, a generalized linear mixed model (GLMM) and the linear mixed model (LMM) for repeated measures were used for vomiting and pain scores, respectively.

Results: There was no statistical significance of POV incidence, requirement of rescue analgesic and pain score between the two groups at any measured intervals. The incidence of POV was 53.3\% during 24 hours in both groups, and was especially $6.7 \%$ and $13.3 \%(\mathrm{P}=0.671)$ during $0-2 \mathrm{hr}$ and $16.7 \%$ and $23.3 \%(\mathrm{P}=0.748)$ during $2-6 \mathrm{hr}$ in group $D$ and group DP, respectively.

Conclusions: A small dose of propofol combined with dexamethasone appears ineffective to preventing POV in pediatric moyamoya patients receiving continuous fentanyl infusion. (Korean J Anesthesiol 2013; 64: 127-132)

Key Words: Dexamethasone, Moyamoya disease, Postoperative vomiting, Propofol.

Received: May 23, 2012. Revised: 1st, September 10, 2012; 2nd, October 2, 2012. Accepted: October 7, 2012.

Corresponding author: Kyeong Tae Min, M.D., Department of Anesthesiology and Pain Medicine, Yonsei University Health System, Anesthesia and Pain Research Institute, Yonsei University College of Medicine, 50, Yonsei-ro, Seodaemun-gu, Seoul 120-752, Korea. Tel: 82-2-2227-4161, Fax: 82-2-312-7185, E-mail: ktmin501@yuhs.ac

This article is a Master's Thesis by Jeongmin Kim.

(c) This is an open-access article distributed under the terms of the Creative Commons Attribution Non-Commercial License (http:// creativecommons.org/licenses/by-nc/3.0/), which permits unrestricted non-commercial use, distribution, and reproduction in any medium, provided the original work is properly cited. 


\section{Introduction}

Moyamoya disease is a rare progressive ischemic vascular disorder predominantly in the territory of the anterior and middle cerebral arteries. Neovascularization procedures such as direct or indirect vascular bypass surgery are effectively practiced in most institutes for these patients, and intraoperative and postoperative management strategies are strictly based on hemodynamic stability and normocarbic status. According to the report by Hayash et al. [1], postoperative neurologic deterioration in moyamoya disease patients is often caused by cerebral hemodynamic changes such as a shift of the watershed area or hyperemia in brain regions. Both inadequate postoperative pain control and emesis activate the sympathetic nervous system and increase the intracranial pressure, and the postoperative care for pain and emesis can be very closely related to their morbidity and mortality of pediatric moyamoya patients $[2,3]$. Continuous intravenous infusion with fentanyl [4] was suggested to be effective for postoperative pain control in pediatric patients, but fentanyl also acts as a risk factor for postoperative nausea and vomiting (PONV) $[5,6]$. For high risk PONV patients, a multimodal approach is recommended [7] because most antiemetics work independently of each other and of the patient's risk factor [8]. But the antiemetic effect of ondansetron is uncertain in pediatric neurosurgical patients [9-11]. It is widely believed that propofol based anesthesia reduces PONV more compared to volatile anesthesia [12]. Furthermore, even a small dose of propofol was reported to possess direct antiemetic effects [13-15], and an adjuvant subhypnotic dose $[16,17]$ or infusion [18] of propofol to dexamethasone reduced emetic events in surgical or chemotherapy patients. For surgical patients, a small dose of propofol combined with dexamethasone was effective to preventing PONV during immediate postoperative periods without delaying anesthetic recovery [17] and would be valuable to neurosurgical patients.

Therefore, we compared the postoperative anti-vomiting effect between dexamethasone alone and dexamethasone with a small dose of propofol in pediatric moyamoya patients who underwent encephalo-duro-arterio-synangiosis (EDAS) surgery and received continuous infusion of fentanyl for postoperative pain.

\section{Materials and Methods}

After approval of the Institutional Review Board and obtaining written informed consent from parents, this study was performed according to the declaration of Helsinki and 67 American Society of Anesthesiologists physical status I or II, diagnosed with moyamoya disease, aged 4-17 year of either sex, scheduled for EDAS surgery were enrolled during May 2009 and May 2010 at a university hospital in this observer-blind prospective, randomized controlled study. Among them, 60 patients were included for data analysis according to our exclusion criteria; presence of neurologic signs or seizure at admission, history of motion sickness or PONV, mental retardation and requirement of postoperative ventilator care (Fig. 1).

Patients fasted for 4-8 hours before surgery according to age. Premedication was not given. As patients arrived at the preinduction room with their parents, thiopental sodium $2 \mathrm{mg} /$

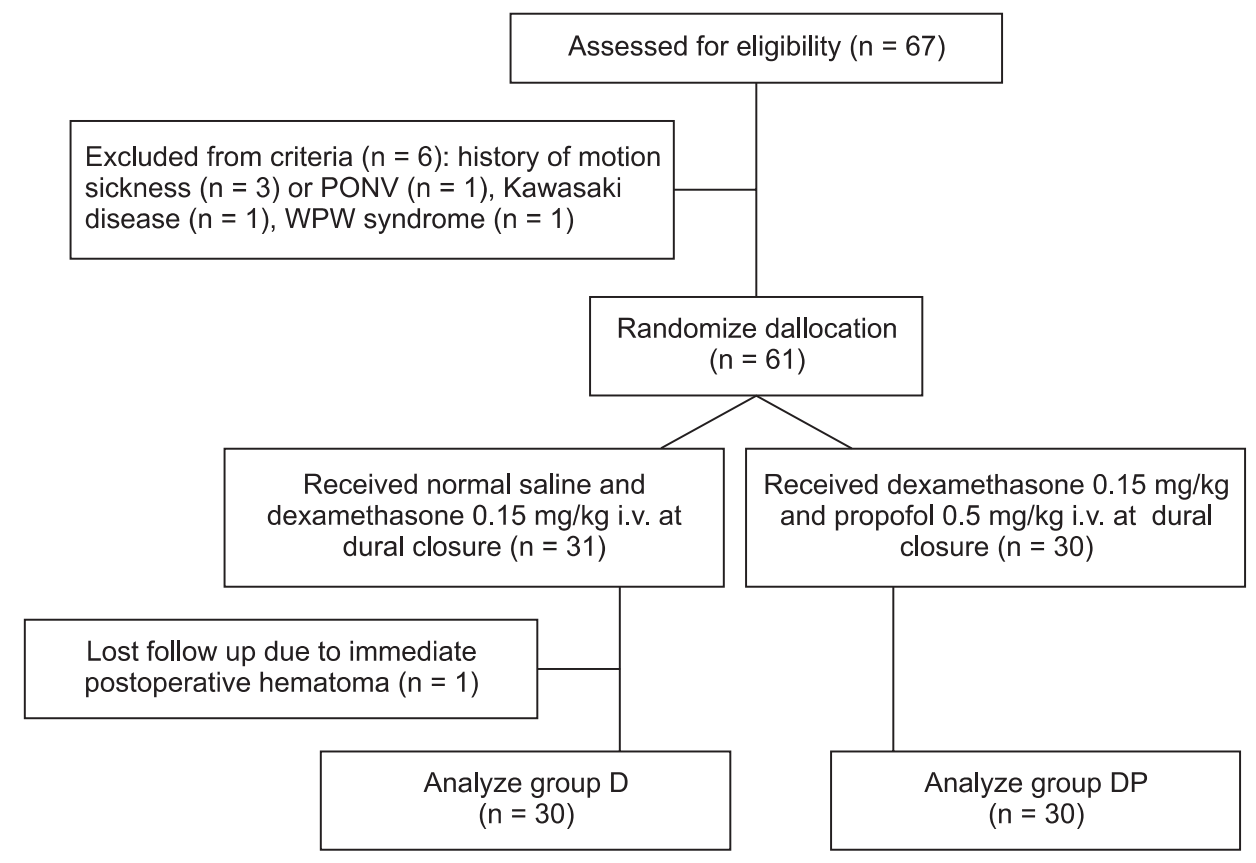

Fig. 1. Flow chart to track participants through randomized trial. 
$\mathrm{kg}$ was administered to children who were crying or anxious about entering the operating room. Anesthesia was induced with intravenous thiopental sodium $3-5 \mathrm{mg} / \mathrm{kg}$ followed by face mask ventilation with sevoflurane in air and oxygen. The trachea was intubated with the aid of rocuronium $0.7 \mathrm{mg} / \mathrm{kg}$. Anesthesia was maintained with sevoflurane $(2-4$ vol\%) in $50 \%$ oxygen and remifentanil infusion $(0.1-0.4 \mu \mathrm{g} / \mathrm{kg} / \mathrm{min})$, and anesthetic depth was adjusted to changes in the hemodynamic variables within $20 \%$ of baseline values. Controlled ventilation was adjusted to maintain end-tidal carbon dioxide partial pressure of 35-40 $\mathrm{mmHg}$. Body temperature was maintained within $36.0-36.7^{\circ} \mathrm{C}$ with air heater. Standard anesthetic monitors of ECG, invasive blood pressure, and pulse oximetry were applied continuously. For postoperative pain control, fentanyl i.v. infusion with a rate of $0.5 \mu \mathrm{g} / \mathrm{kg} / \mathrm{hr}$ (with the maximum dose of $600 \mu \mathrm{g} /$ day) began at dural closure and continued for 48 hours postoperatively. At the completion of surgery, residual muscle relaxation was completely reversed with neostigmine $0.02 \mathrm{mg} / \mathrm{kg}$ and atropine $0.01 \mathrm{mg} / \mathrm{kg}$ after confirming the recovery of neuromuscular function using a nerve stimulator (TOF-Watch SX, Organon Ireland Limited, Dublin, Ireland). After completion of the head dressing, administration of remifentanil and sevoflurane was discontinued. The trachea was extubated by the attending anesthesiologist's assessment that the patient regained spontaneous respiration adequately. Patients stayed in the postoperative care unit (PACU) for at least 1 hour, and were moved to a general ward.

Patients were randomly allocated into two groups with computer-generated random numbers. At dural closure, normal saline and dexamethasone $0.15 \mathrm{mg} / \mathrm{kg}$ (group D) or propofol $0.5 \mathrm{mg} / \mathrm{kg}$ and dexamethasone $0.15 \mathrm{mg} / \mathrm{kg}$ (group DP) were administered. Nursing staffs in PACU and ward, who cared for the patients and knew of this clinical study but were blinded to the patient's group, recorded every episode of vomiting for 24 hours (at intervals of $0-2 \mathrm{hr}, 2-6 \mathrm{hr}, 6-12 \mathrm{hr}$ and $12-24$ $\mathrm{hr}$ ). Vomiting was defined as forced gastric and esophageal movement with either the expulsion of gastric contents or not. When vomiting occurred more than twice in 30 minutes or patients were intolerant to vomiting, metoclopramide 0.15 $\mathrm{mg} / \mathrm{kg}$ was administered as a rescue antiemetic. In addition, numeric scaled pain scores ( $0-5$, Wong-Baker's facial expression scale $[4,19]$ ) were evaluated. Ketorolac $1 \mathrm{mg} / \mathrm{kg}$ was intravenously administered as a rescue analgesic on the basis of the requirements of the children's care giver or pain score of more than 3.

Collected data included gender, age, weight, height, duration of anesthesia and operation, occurrence of postoperative vomiting (POV), pain severity, and number of patients who were administered with rescue antiemetic or analgesic. Recovery time (from discontinuation of anesthetics to awakening or eye opening with physical activities) was recorded.

\section{Statistical analysis}

We used the Student t-test and chi-square test or Fisher's exact test for comparison of mean data and dichotomous data, respectively. For further analysis of the incidence of vomiting and pain score by the measuring time $(0-2,2-6,6-12$ and $12-24 \mathrm{hr}$ ), we also used a generalized linear mixed model (GLMM) for repeated measure vomiting (applied with binomial response distribution and logit link function) and a linear mixed model (LMM) for a repeated pain measure score. A P value of less than 0.05 was considered significant. Statistical analysis was performed with Sigma stat v3.0 (Systat software, San Jose, Ca, USA) and a proc glimmix and proc mixed program (SAS 9.2 for Windows, SAS Institute Inc., Cary, NC, USA).

\section{Results}

In comparison of demographic data between the two groups,

Table 1. Demographic Data and Postoperative Rescue Medications

\begin{tabular}{|c|c|c|c|}
\hline & Group D $(\mathrm{n}=30)$ & Group DP $(\mathrm{n}=30)$ & $P$ value \\
\hline $\operatorname{Sex}(M / F) *$ & $16 / 14$ & $13 / 17$ & 0.438 \\
\hline $\operatorname{Age}(\mathrm{yr})^{\dagger}$ & $8.1 \pm 3.4$ & $10.0 \pm 3.9$ & 0.052 \\
\hline $\mathrm{Wt}(\mathrm{kg})^{\dagger}$ & $27.3 \pm 11.5$ & $34.7 \pm 15.9$ & 0.042 \\
\hline $\mathrm{Ht}(\mathrm{cm})^{\dagger}$ & $127.5 \pm 21.4$ & $133.7 \pm 20.5$ & 0.257 \\
\hline Op. duration $(\min )^{\dagger}$ & $119.3 \pm 19.3$ & $113.0 \pm 26.9$ & 0.299 \\
\hline Anes. duration $(\mathrm{min})^{\dagger}$ & $161.3 \pm 23.3$ & $165.1 \pm 26.5$ & 0.554 \\
\hline Recovery time $(\min )^{\dagger}$ & $14.3 \pm 8.4$ & $12.1 \pm 10.5$ & 0.382 \\
\hline \multicolumn{4}{|l|}{ Postoperative analgesics/antiemetic } \\
\hline Fentanyl consumption $(\mu \mathrm{g} / \mathrm{kg})^{\dagger}$ & $10.7 \pm 2.6$ & $11.1 \pm 2.0$ & 0.534 \\
\hline Rescue analgesic needed (no. of patients) ${ }^{\dagger}$ & $14(46.7 \%)$ & $8(26.7 \%)$ & 0.180 \\
\hline Rescue antiemetic needed (no. of patients) ${ }^{\ddagger}$ & $14(46.7 \%)$ & $13(43.3 \%)$ & 1.0 \\
\hline
\end{tabular}

Data are mean \pm SDM unless addressed. Statistical analyses were performed using *Chi-square test, ${ }^{\dagger}$ Student t-test, or ${ }^{\dagger}$ Fisher's exact test. Group D and DP represent dexamethasone only treated- and dexamethasone and propofol treated- patients, respectively. 
patients of Group D weighed less than those of Group DP (27.3 $\mathrm{kg}$ vs. $34.7 \mathrm{~kg}, \mathrm{P}=0.042$ ). Otherwise, there were no differences between the two groups in demographic data. Recovery time from anesthesia, fentanyl consumption dose, and patient number who required rescue analgesic and antiemetic were not different between the two groups (Table 1). No patients showed oxygen desaturation of $\mathrm{SpO}_{2}<90 \%$ during the recovery period and at PACU.

The Fisher's exact test showed no difference of incidence of POV between two groups at any measured intervals with the overall incidence of POV of 53.3\% in both groups during 24 hours. GLMM analysis revealed that the incidence of vomiting during the postoperative $0-2 \mathrm{hr}$ was lower than that during the $6-12 \mathrm{hr}(\mathrm{P}<0.05)$ as a factor of measured time regardless of group, but the interactive effect between groups and measured time was also insignificant $(\mathrm{P}>0.05)$.

Postoperative pain scores during $0-2$ and $2-6 \mathrm{hr}$ were higher than those during $12-24 \mathrm{hr}$ in both groups $(\mathrm{P}=0.001)$ but did not differ between the two groups at measured intervals (Fig. 2).

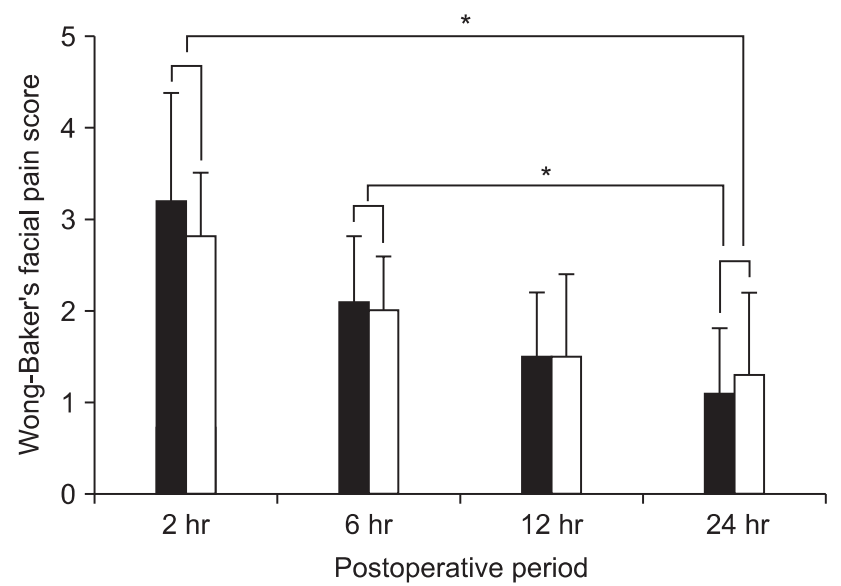

Fig. 2. Postoperative Wong-Baker's facial pain score. Data are presented as the mean and SDM. Statistical analysis with linear mixed model (LMM) revealed that pain scores at early postoperative periods $(0-6 \mathrm{hr})$ were higher than those at $24 \mathrm{hr}$ in both groups $(* \mathrm{P}=$ 0.001 ) but did not differ between group $\mathrm{D}$ (black box, dexamethasone alone, $\mathrm{n}=30$ ) and group DP (white box, dexamethasone and propofol, $\mathrm{n}=30$ ) at any measured intervals.

\section{Discussion}

Our study failed to observe that adjuvant use of propofol 0.5 $\mathrm{mg} / \mathrm{kg}$ would increase the antiemetic effect of dexamethasone in pediatric moyamoya patients who underwent EDAS surgery under intraoperative use of sevoflurane and remifentanil and received fentanyl based postoperative analgesia.

Moyamoya disease is diagnosed with unique cerebral angiographic findings frequently accompanied with transient ischemic attacks or seizures. The nature of this disease is progressive, and neovascularization procedures such as direct or indirect vascular bypass surgery prevent further aggravation and improve the occurrence of neurologic symptoms. Since the postoperative neurologic deterioration may be related with dynamic changes in bypassed vasculatures [1], postoperative care for adequate pain and PONV control is critically important. For high risk patients to PONV, multiple drug combinations with dexamethasone, dimenhydrinate, perphenazine, and serotonin type 3 receptor antagonists has been suggested to prevent postoperative emesis [20]. Nevertheless, ondansetron, a class of serotonin type 3 receptor antagonists, seems to be very effective in non-neurosurgical cases, it is still controversial for neurosurgical patients $[9,11]$. On the other hand, propofol was suggested as another candidate for drug combinations with dexamethasone to prevent postoperative emesis in some circumstances [16-18], especially during immediate postoperative periods rather than delayed periods. Therefore, we hypothesized that adjuvant use of propofol $0.5 \mathrm{mg} / \mathrm{kg}$ to prophylactic dexamethasone might reduce the incidence of POV further, especially during immediate postoperative periods, in pediatric moyamoya disease undergoing bypass surgery. This study must be the first report on the incidence of POV for them. The enrolled patients belong to a very high risk category of POV because of many well known risk factors or conditions; status as children, using sevoflurane and remifentanil in anesthetic maintenance, using fentanyl as postoperative analgesia, and undergoing craniotomy. The overall incidence of POV during 24 hours in our moyamoya patients was $53.3 \%$ regardless of groups (Table 2) and was slightly lower than $66 \%$ of incidence

Table 2. Incidence and Odd Ratios of Postoperative Vomiting

\begin{tabular}{|c|c|c|c|c|}
\hline \multirow{2}{*}{ Postoperative period } & \multicolumn{4}{|c|}{ Vomiting } \\
\hline & Group D $(n=30)$ & Group DP $(n=30)$ & P value* & $\mathrm{OR}^{\dagger}(95 \% \mathrm{CI})$ \\
\hline $0-2 \mathrm{hr}$ & $6.7 \%(1 / 1)$ & $13.3 \%(3 / 1)$ & 0.671 & $0.464(0.078-2.751)$ \\
\hline $2-6 \mathrm{hr}$ & $16.7 \%(2 / 3)$ & $23.3 \%(3 / 4)$ & 0.748 & $0.657(0.183-2.363)$ \\
\hline $6-12 \mathrm{hr}$ & $40.0 \%(5 / 7)$ & $26.7 \%(5 / 3)$ & 0.412 & $1.833(0.616-5.453)$ \\
\hline $12-24 \mathrm{hr}$ & $30.0 \%(4 / 5)$ & $13.3 \%(2 / 2)$ & 0.209 & $2.786(0.751-10.331)$ \\
\hline Overall & $53.3 \%(9 / 7)$ & $53.3 \%(7 / 9)$ & 1.0 & \\
\hline
\end{tabular}

Data are \% of patients (number of patients, male/female). *Fisher's exact test with two sided analysis was performed. OR and CI refer to odd ratio and confidence interval, respectively. ${ }^{\dagger}$ OR presents the ratio of group D over group DP. 
in children undergoing craniotomy [11] probably due to less severe and shorter surgical procedures in spite of the fact that postoperative use of opioids would affect the incidence of POV in a dose-dependent manner [21]. We found similar requirements of rescue antiemetic and POV incidence at any measured intervals between the two groups with Fisher's exact test. Contrary to previous studies which showed the antiemetic effect of a small dose of propofol combined with dexamethasone [16-18] in some clinical situations, our patients differ from them in some aspects; undergoing neurosurgery, being pediatric patients, and receiving fentanyl as postoperative analgesia. Even though that risk factors of postoperative emesis relating to surgical anesthesia and analgesia such as use of sevoflurane and remifentanil for anesthetic maintenance and fentanyl as postoperative analgesia would contribute independently to postoperative nausea and vomiting according to postoperative periods [5], it is uncertain whether small dose of propofol would potentiate the fentanyl induced vomiting during postoperative $0-6$ hours (Table 2) because propofol $0.5 \mathrm{mg} / \mathrm{kg}$ combined with dexamethasone $4 \mathrm{mg}$ showed an antiemetic effect during postoperative $0-4$ hours but not thereafter after middle ear surgery [17]. But in a later study, they compared propofol and dexamethasone with the placebo group and the patients were neurologically intact adults and had not received fentanyl as postoperative analgesia. With GLMM analysis, in spite of insignificant interaction effects between groups and the time factor, POV occurred less during early postoperative periods. Contrary to our expectations, there was rather a tendency for more patients of group DP than of group D vomited during the postoperative $0-6$ hours and reversed thereafter (Table 2). It was hard to explain the reasons behind this postoperative vomiting tendency. Therefore, while seeking multi-antiemetic interventions should be maintained for high risk pediatric neurosurgical patients, the reduction of postoperative opioid doses by adding non-opioids such as non steroidal antiinflammatory agents [22] or by applying scalp nerve blocks [23] also needs to be considered.

Our study has some limitations. First, even though moyamoya disease is uncommon, our sample size may be too small to completely exclude any beneficial effect of small doses of propofol . According to the incidence of POV during early postoperative periods ( $0-6$ hours), a post-hoc power analysis showed $55 \%$ power to validate our results and a minimum of 25 patients per group would be required to exclude the possible beneficial effect of propofol (Type II error). Therefore, this study may provide clinical significance as a pilot study. Second, we did not measure the plasma concentration of propofol to show the relationship between plasma concentration of propofol and its antiemetic effect because an antiemetic effect of propofol was shown at a plasma concentration of $343 \mathrm{ng} / \mathrm{ml}$ which was possible to reach with a bolus dose of $10 \mathrm{mg}$ followed by an infusion of $10 \mathrm{mg} / \mathrm{kg} / \mathrm{min}$ in adults [24]. In this study, the dose of propofol might be too small to achieve plasma concentration to show its antiemetic effect because the awakening time was not different between the two groups. But multimodal regimens with a higher bolus dose or infusion of propofol combined with dexamethasome may not be appropriate because the antiemetic effect of subhypnotic propofol was associated with prolonged orientation time [15], Third, we did not measure the effect of propofol on nausea because it is not easy to measure the incidence of nausea in pediatric patients. Because the exact mechanisms of postoperative nausea and vomiting associated with separate risk factors are unclear and unrelated with each other, we could not exclude any favorable effect toward postoperative nausea in these patients. Forth, Lejus et al. [25] recently published three independent risk factors of POV (female, urological surgery and age of older than 3 years) in non-neurosurgical pediatric patients receiving continuous intravenous morphine. In this study, patients of Group D weighed less than those of Group DP (27.3 kg vs. 34.7 $\mathrm{kg}, \mathrm{P}=0.042)$, perhaps due to a slightly younger group in $\mathrm{D}$ patients (8.1 yr vs. $10.0 \mathrm{yr}, \mathrm{P}=0.052)$. However this would not influence the results. Even though there were no differences in sex distribution and mean age between the two groups in demographic data (Table 1) and similar sexual distribution at each measured interval between groups (Table 2) perhaps due to the small size of enrolled patients, we could not measure the exact impact of the sex distributions of ages over puberty in our results.

In conclusion, the administration of small doses of propofol combined with dexamethasone during dural closure is not more effective than dexamethasone alone for the prevention of postoperative vomiting in pediatric moyamoya surgical patients receiving fentanyl as a postoperative analgesic. However further study with a large sample size may be needed.

\section{Acknowledgments}

Authors thanks to Hye Sun Lee, Biostatistician, Biostatistics Collaboration Unit for the assistance of statistical analysis.

\section{References}

1. Hayashi T, Shirane R, Fujimura M, Tominaga T. Postoperative neurological deterioration in pediatric moyamoya disease: watershed shift and hyperperfusion. J Neurosurg Pediatr 2010; 6: 73-81.

2. Kansha M, Irita K, Takahashi S, Matsushima T. Anesthetic management of children with moyamoya disease. Clin Neurol Neurosurg 1997; 99 Suppl 2: S110-3.

3. Parray T, Martin TW, Siddiqui S. Moyamoya disease: a review of the 
disease and anesthetic management. J Neurosurg Anesthesiol 2011; 23: 100-9.

4. Choi SH, Lee WK, Lee SJ, Bai SJ, Lee SH, Park BY, et al. Parentcontrolled analgesia in children undergoing cleft palate repair. J Korean Med Sci 2008; 23: 122-5.

5. Apfel CC, Kranke P, Katz MH, Goepfert C, Papenfuss T, Rauch S, et al. Volatile anaesthetics may be the main cause of early but not delayed postoperative vomiting: a randomized controlled trial of factorial design. Br J Anaesth 2002; 88: 659-68.

6. Sakellaris G, Georgogianaki P, Astyrakaki E, Michalakis M, Dede O, Alegakis A, et al. Prevention of post-operative nausea and vomiting in children--a prospective randomized double-blind study. Acta Paediatr 2008; 97: 801-4.

7. Apfel CC, Kranke P, Piper S, Rusch D, Kerger H, Steinfath M, et al. Nausea and vomiting in the postoperative phase. Expert- and evidence-based recommendations for prophylaxis and therapy. Anaesthesist 2007; 56: 1170-80.

8. Apfel CC, Korttila K, Abdalla M, Kerger H, Turan A, Vedder I, et al. A factorial trial of six interventions for the prevention of postoperative nausea and vomiting. N Engl J Med 2004; 350: 2441-51.

9. Subramaniam K, Pandia MP, Dash M, Dash HH, Bithal PK, Bhatia A, et al. Scheduled prophylactic ondansetron administration did not improve its antiemetic efficacy after intracranial tumour resection surgery in children. Eur J Anaesthesiol 2007; 24: 615-9.

10. Neufeld SM, Newburn-Cook CV. The efficacy of 5-HT3 receptor antagonists for the prevention of postoperative nausea and vomiting after craniotomy: a meta-analysis. J Neurosurg Anesthesiol 2007; 19: 10-7.

11. Furst SR, Sullivan LJ, Soriano SG, McDermott JS, Adelson PD, Rockoff MA. Effects of ondansetron on emesis in the first 24 hours after craniotomy in children. Anesth Analg 1996; 83: 325-8.

12. Shinn HK, Lee MH, Moon SY, Hwang SI, Lee CS, Lim HK, et al. Post-operative nausea and vomiting after gynecologic laparoscopic surgery: comparison between propofol and sevoflurane. Korean J Anesthesiol 2011; 60: 36-40.

13. Borgeat A, Wilder-Smith OH, Saiah M, Rifat K. Subhypnotic doses of propofol possess direct antiemetic properties. Anesth Analg 1992; 74: 539-41.

14. Gan TJ, El-Molem H, Ray J, Glass PS. Patient-controlled antiemesis: a randomized, double-blind comparison of two doses of propofol versus placebo. Anesthesiology 1999; 90: 1564-70.

15. Song D, Whitten CW, White PF, Yu SY, Zarate E. Antiemetic activity of propofol after sevoflurane and desflurane anesthesia for outpatient laparoscopic cholecystectomy. Anesthesiology 1998; 89: 838-43.

16. Borgeat A, Wilder-Smith O, Forni M, Suter PM. Adjuvant propofol enables better control of nausea and emesis secondary to chemotherapy for breast cancer. Can J Anaesth 1994; 41: 1117-9.

17. Arslan M, Demir ME. Prevention of postoperative nausea and vomiting with a small dose of propofol combined with dexamethasone $4 \mathrm{mg}$ or dexamethasone $8 \mathrm{mg}$ in patients undergoing middle ear surgery: a prospective, randomized, doubleblind study. Bratisl Lek Listy 2011; 112: 332-6.

18. Erdem AF, Yoruk O, Alici HA, Cesur M, Atalay C, Altas E, et al. Subhypnotic propofol infusion plus dexamethasone is more effective than dexamethasone alone for the prevention of vomiting in children after tonsillectomy. Paediatr Anaesth 2008; 18: 878-83.

19. Wong DL, Baker CM. Pain in children: comparison of assessment scales. Pediatr Nurs 1988; 14: 9-17.

20. Kovac AL. Management of postoperative nausea and vomiting in children. Paediatr Drugs 2007; 9: 47-69.

21. Roberts GW, Bekker TB, Carlsen HH, Moffatt CH, Slattery PJ, McClure AF. Postoperative nausea and vomiting are strongly influenced by postoperative opioid use in a dose-related manner. Anesth Analg 2005; 101: 1343-8.

22. White PF. The changing role of non-opioid analgesic techniques in the management of postoperative pain. Anesth Analg 2005; 101(5 Suppl): S5-22.

23. Ahn HJ, Kim JA, Lee JJ, Kim HS, Shin HJ, Chung IS, et al. Effect of preoperative skull block on pediatric moyamoya disease. J Neurosurg Pediatr 2008; 2: 37-41.

24. Gan TJ, Glass PS, Howell ST, Canada AT, Grant AP, Ginsberg B. Determination of plasma concentrations of propofol associated with $50 \%$ reduction in postoperative nausea. Anesthesiology 1997; 87: 779-84.

25. Lejus C, Tissot M, Roquilly A, Populaire C, Guillaud C, De Windt A, et al. Risk factors of postoperative vomiting in children receiving continuous intravenous morphine. Minerva Anestesiol 2012; 78 : 160-7. 